\title{
ESTABELECIMENTO DE LIMITES COMO MEDIDA TERAPÊUTICA DE RELACIONAMENTO ENFERMEIRA-PACIENTE
}

\author{
Evalda Cançado Arantes* \\ Maguida Costa Stefanelli** \\ Ilza Marlene Kuae Fukuda**
}

ARANTES, E. C.; STEFANELLI, M. C.; FUKUDA, I. M. K. Estabelecimento de limites como medida terapêutica de relacionamento enfermeira-paciente. Rev. Esc. Enf. USP, São Paulo, 15(2):155-160, 1981.

As autoras abordam a importância e a necessidade da colocação de limites como medida terapêutica no relacionamento enfermeira-paciente. Apresentam uma revisão de literatura sobre o assunto, discorrendo a respeito dos passos e técnicas na aplicação desta medida terapêutica.

\section{INTRODUÇÃO}

Atualmente ouve-se falar, com freqüência, em liberdade plena em todas as atividades da vida humana. Talvez seja por isso que, quando se fala em ambiente terapêutico em hospital psiquiátrico, a noção de permissividade venha sempre associada à idéia de liberdade total, com o pressuposto de que o paciente tem liberdade para agir da maneira que quiser. Permissividade e liberdade total, entretanto, tem conseqüências distintas em hospital psiquiátrico. Entende-se por permissividade, em hospital psiquiátrico, a aceitação incondicional do paciente, pela enfermeira, como um ser humano com todas suas peculiaridades. Contudo, isto não significa que ela deva aprovar todas as manifestações de comportamento expressas pelo paciente, o que seria liberdade total. Permissividade também deve ter limites, como afirma JOHNSTON (1971).

Para que o ambiente hospitalar ofereça segurança e seja útil ao paciente, as pessoas da equipe terapêutica devem concentrar seus esforços no sentido de permitir o seu desenvolvimento emocional. Assim, as atividades e a política da unidade devem ser determinadas para promover relacionamento grupal saudável.

Permissividade em ambiente terapêutico hospitalar implica na limitação do comportamento do paciente, pela enfermeira, quando necessário, com o objetivo de desenvolver padrões de comportamnto socialmente mais aceitos. Dizemos "enfermeira" porque é o pessoal de enfermagem que cuida do paciente 24 horas por dia. Por outro lado, segundo WERNER (1966), o estabelecimento de limites contribui, de maneira valiosa, para a criação de um ambiente no qual o paciente se sinta seguro.

\section{Conceito}

O estabelecimento de limites, de acordo com LYON (1970), é o processo terapêutico pelo qual alguém com competência determina limites, artificiais e temporários, às manifestações de comportamento de outra pessoa.

* Professor Assistente Doutor da disciplina Enfermagem Psiquiátrica da EEUSP.

** Professor Assistente da disciplina Enfermagem Psiquiátrica da EEUSP. Mestre em Enfermagem. 
RUESCH (1964) afirma que todo ser tende a expandir-se no território dos outros seres, a menos que lhe anteponham limites e o ensinem a defender suas próprias fronteiras e a respeitar as alheias. WERNER (1966) declara que, quando a enfermeira determina para o paciente os limites de suas manifestaçoes de comportamento, diminui, com isso, a ansiedade deste, proporcionando-lhe proteção e segurança, o que poderá ser percebido no desenvolvimento de relacionamento saudável com as pessoas.

Por outro lado, os limites terminam por formar um esquema referencial dentro do qual a pessoa é livre para agir o mais adequadamente possível, aprender novos padrões de comportamento, tornando-se, dessa forma capaz de desenvolver a própria identidade e aumentar sua auto-estima (LYON, 1970).

\section{NECESSIDADE DO ESTABELECIMENTO DE LIMITES}

Segurança, como afirma MASLOW (1970), é uma necessidade básica do ser humano que ocupa segundo lugar dentro da hierarquia, por ele determinada, das necessidades humanas básicas. Devem estas ser satisfeitas, para que a pessoa atinja sua potencialidade máxima.

De acordo com COMBS et alii (1971), toda situação de vida tem limites e as pessoas necessitam deles. 0 conhecimento dos limites de uma situação provê a pessoa de sentimento de segurança, o que lhe permite agir com liberdade.

A necessidade de limites está intimamente relacionada com a necessidade básica que todas as pessoas experimentam de se sentirem seguras e confiantes.

Liberdade dentro de limites permite o desenvolvimento da segurança, oferecendo condições para que a pessoa possa confiar nas outras e $\mathrm{cm}$ si mesma, o que a leva a alcançar senso de integridade como um ser independente (SULJIVAN, 1953).

Muitas manifestações de comportamento surgem motivadas pela procura de segurança, quando esta necessidade básica não foi satisfeita. A pessoa que necessita de assistência psiquiátrica, geralmente, manifesta regressão, em níveis variáveis, em seu comportamento. Vê-se à frente de uma situação nova, com intensa carga de ansiedade, da qual procura livrar-se por meio de várias tentativas. Quando estas não são aceitas, e as necessidades não são adequadamente atendidas pela enfermeira, podem provocar na pessoa maior ansiedade e insegurança (GAMEIRO, 1968).

O ambiente hospitalar e o relacionamento enfermeira-paciente deverão oferecer a este clima de segurança. A enfermeira deve informar ao paciente as manifestações de comportamento esperadas e limitar as não aceitas. Dentro desta es. trutura, o paciente pode experimentar a segurança que não tivera no passado. $O$ estabelecimento de limites é um aspecto do relacionamento enfermeira-paciente que irá ajudá-lo a diminuir seu nível de ansiedade, proporcionando-lhe, assim, condições para testar padrões de comportamento mais adequados; desta forma ele terá aceitação por parte das pessoas com as quais convive. Além disso, o paciente mudará o conceito que tem de si, orientará sua própria vida e terá oportunidade de experimentar sucesso onde não obtivera antes. 


\section{QUANDO ESTABELECER LIMITES}

O estabelecimento de limites deve ser encarado como parte da assistência integral ao paciente, e não apenas como simples cumprimento das regras hospitalares, e aplicado somente quando há manifestações de comportamento consideradas anti-sociais ou destrutivas.

Segundo BURGESS \& LAZARE (1976), a enfermeira, ao atuar em unidade psiquiátrica, comumente vê-se em face de manifestações de comportamento em que precisa decidir se estas devem ser estimuladas ou limitadas.

Com base em nossas experiências no relacionamento com pacientes internados em hospital psiquiátrico, e de acordo com KUMLER (1963), WILEY (1967), HOFLING et alii (1970), LYON (1970), BURGUES \& LAZARE (1976), ZAMORA (1978),McMORROW (1981), abordamos, a seguir, algumas situações em que há necessidade da enfermeira intervir no comportamento manifestado pelo paciente.

- Quando transgride normas e rotinas da unidade de internação.

- Sempre que se torna excessivamente reivindicador ou exige privilégios.

- Toda vez que tenta assumir a liderança da unidade.

- Quando instiga os pacientes uns constra os outros e contra as pessoas da equipe que os assiste ou quando provoca desarmonia entre as pessoas.

- Assim que começa a manifestar comportamento que possa acarretar injúrias para si e para os demais. dade.

- Sempre que manifesta comportamento que denota agitação e agressivi-

- Toda vez que suas manifestações de comportamento provocam ansiedade e irritação na enfermeira e nas demais pessoas da unidade. tomas.

- Sempre que o tema da conversação gira somente em torno de seus sin-

- Quando expressa sentimentos de culpa ou que revelam depreciação de si mesmo. mente.

- Quando não mantém discurso cocrente ou muda de assunto constante-

- Toda vez que recusa submeter-se a tratamento.

- Sempre que manifesta desvio de comportamento sexual.

- Quando o "teste" e a "manipulação" são uma constante no seu comportamento, como por exemplo, elogiar e presentear inoportuna ou inadequadamente as pessoas da equipe.

- Toda vez que apresenta qualquer outra manifestação de comportamento não aceita socialmente. 


\section{PASSOS E TÉCNICAS NO ESTABELECIMENTO DE LIMITES}

A enfermeira deve estar ciente de que o estabelecimento de limites não é mera punição e sim o desenvolvimento de padrões de comportamento socialmente aceitos e transmitir ao paciente esse objetivo.

Para RUESCH (1964), o controle do comportamento não tem por objetivo inibir a ação mas desenvolver uma melhor quantificação e sincronização das ações, para uma tomada de decisão mais adequada.

WERNER (1966), LYON (1970), JOEL \& COLLINS (1978) e ZAMORA (1978), entre outros, determinam os passos e as técnicas para o estabelecimento de limites ao comportamento manifestado pelo paciente. Afirmam tais autores que, antes de ser aplicada qualquer medida de enfermagem como limite ao comportamento do paciente, a enfermeira tem que analisar, rapida e objetivamente, a real necessidade dessa medida. Além disso, a enfermeira deve acreditar e transmitir ao paciente a crença de que a medida tomada irá provocar mudança nos padróes de comportamento manifestados por ele.

A enfermeira deve pensar ativamente sobre se o limite é uma medida terapêutica que visa provocar mudança no comportamento do paciente; se não é uma medida punitiva ou se não estaria apenas a serviço da segurança da própria enfermeira. É sempre importante que a enfermeira conheça suas atitudes e reações em relação à autoridade, para que elas não interfiram negativamente na colocação dos limites.

Toda vez que a enfermeira tiver que intervir no comportamento do paciente, terá que considerar as peculiaridades do ambiente, a situação de cada paciente, além das mensagens que o paciente tenta transmitir com suas manifestações de comportamento.

O passo seguinte consiste em comunicar ao paciente o comportamento esperado, definindo para ele claramente e com firmeza o resultado esperado. $\mathrm{O}$ comportamento socialmente aceito deve ser comunicado pela enfermeira e percebido pelo paciente; o tom de voz empregado neste momento é da máxima importância; a enfermcira não deve deixar transparecer ansiedade ou irritação e deve falar de modo que transmita ao paciente a crença na sua mudança de comportamento; o limite deve ser colocado com habilidade, sem irritação, pois irritação gera mais irritação e cria-se um círculo vicioso que dificulta a consecução dos objetivos, em qualquer situação.

O próximo passo é operacionalizar o limile. Após haver identificado a real necessidade do estabelecimento do limite e haver comunicado ao paciente a expectativa de sua mudança de comportamento, se ele não apresentar a mudança desejada o limite deve ser colocado, com cuidado para que o esquema de valores pessoais da enfermeira não interfira em sua intervenção. A enfermeira tem que oferecer uma alternativa de padrão de comportamento aceitável e adequada para o momento.

A enfermeira tem que acreditar firmemente em seus propósitos, para que o paciente perceba, nos seus atos, real e positivo significado no limite estabelecido. Se ela demonstrar insegurança, a ansiedade do paciente aumentará e, conseqüen- 
temente, seu sentimento de insegurança, o que poderá levá-lo a desafiar ou testar a capacidade da enfermeira.

Quando as condições do paciente o permitirem, pode ser com ele discutido seu comportamento, o limite a ser imposto e suas conseqüências. Isto proporcionará ao paciente uma visão de sua atuação e das respectivas conseqüências sendo a ele oferecido, então, oportunidade de tomar decisão, ciente do que lhe poderá acontecer.

Para BURGUESS \& LAZARE (1976), muitas vezes esta discussão poderá fornecer à enfermeira indícios do que o paciente pretende fazer e facilitar a este sua tomada de decisão.

Outro passo relevante é ajudar o paciente a compreender a razão da colocação do limite.

O limite só atingirá plenamente seu valor terapêutico se o paciente compreender o porquê de sua colocação. Não importa quais sejam as manifestações de comportamento apresentadas pelo paciente, para que sempre lhe seja dito o que está sendo feito e o objetivo em mente. Estas medidas visam a proteção do paciente e dos demais, bem como sua aceitação pelo grupo e, como conseqüência, seu bem-estar. Com isto, a enfermeira estará respeitando a condição de ser humano do paciente e valorizando-o como pessoa que tem direito de saber o que está sendo feito com ele.

O passo seguinte é fazer o paciente cumprir o limite estabelecido.

Uma vez que a enfermeira tenha optado pela colocação de determinado limite ao comportamento do paciente, deve o mesmo ser imposto o mais rápido e seguramente possivel. Esta medida precisa, portanto, ser realística, razoável e ter conseqüências previsíveis. Estabelecido o limite, este tem que ser respeitado pelo paciente.

É necessário que haja coerência e consistência na conduta de todo o pessoal que assiste o paciente que constituem o próximo passo no estabelecimento de limite. Segundo JOHNSTON (1971), a falta de limites ou limites colocados inconsistentemente impedem o desenvolvimento de características básicas da personalidade.

A consistência deve perdurar enquanto persistir o comportamento não aceito; sempre que o paciente manifestá-lo, a pessoa que o assiste deve colocar o limite estipulado. Se não houver homogeneidade de ações, o paciente sentir-se-á inseguro, poderá colocar uns contra os outros, além de desenvolver sentimento de desconfiança em relação à equipe que o assiste.

A avaliação é o passo final da técnica de colocação de limites.

Nem sempre o paciente aceita a imposição de limites ao seu comportamento, portanto, a avaliação do limite deve ser contínua e não baseada apenas na reação inicial por ele apresentada.

A medida que as mudanças de comportamento propostas pelo limite tornamse parte integrante do comportamento do paciente, o controle externo deve di- 
minuir de intensidade e o próprio paciente deve assumir a responsabilidade de suas ações.

Esses são, em linhas gerais, os passos e técnicas para o estabelecimento de limites.

Finalizando, a enfermeira deve sempre ter em mente que cada paciente $\dot{e}$ um ser humano único, particular, e que, por este motivo, o estabelecimento de limites deve ser flexível, dentro deste esquema referencial básico. 0 importante é transmitir, ao paciente segurança para poder atuar livremente dentro dos limites impostos.

ARANTES, E. C.; STEFANELlI, M. C.; FUKUDA, I. M. K. Setting limits as a therapeutic measure in the nurse-patient relationship. Rev. Esc. Enf. USP, São Paulo, $15(2): 155-160,1981$.

The authors discuss the importance and the necessity of stablishing limits as therapeutic tool in the nurse-patient relationship. They review the literature on the subject and outline the steps and techniques recommended in the application of such tools.

\section{REFERENCIAS BIBLIOGRAFICAS}

BURGESS, A. W. \& LAZARE, A. Techniques in the therapeutic process. In: in the hospital and the community. 2. ed., Englewood Cliff, Prentice-Hall, 1976. p. 108-28.

COMBS, A. W. et alii. Establishing helping relationships. In: 107 Helping relationships: basic concepts for the helping profissions. Boston, Allyn and Bacon, 1971. p. 210-31.

GAMEIRO, A. O doente e as suas reações a doença: fatores psicológicos e sociais das doenças. Medicina psicossomática. In: Notas de psicologia. Telhal, 1968. cap. 19, p. 184-90 (mimeografado).

HOFLING, C. K. et alit. Comprensión de las relaciones entre enfermera y paciente. In: - Enfermería psiquiátrica. 2. ed., México, Interamericana, 1970. p. 23-60.

JOEL, L. A. \& COLLINS, D. L. Early childhood. In: - Psychiatric nursing: theory and application. New York, McGraw-Hill Book, 1978. cap. 3, p. 26-34.

JOHNSTON, M. K. Principles of psychiatric nursing. In: 2 . Mental health \& mental illness. Philadelphia, J. B. Lippincott, 1971. cap. 26, p. 206-10.

KUMLER, F. R. An interpersonal interpretation of manipulation. In: BURD, S. F. \& MARSHALL, M. Some clinical approaches to pschyatric nursing. London, Macmillan, 1963. p. 116-24.

LYON, G. G. Limit setting as a therapeutic tool .J. P. N. and Mental Health Services, New York, 8 (6): 17-24, Nov./Dec. 1970.

MASLOW, A. H. A theory of human motivation. Motivation and personality. 2. ed. New York, Harper \& Row, 1970 , p. 35-58.

McMORROW, M. E. The manipulative patient. Amer. J. Nurs., New York, 81 (6): 1188-90, June 1981.

RUESCH, J. Educación y crescimiento. In: - Comunicación terapéutica. Buenos Aires, Paidós, 1964. cap. 12, p. 203-24.

SULLIVAN, H. S. The juvenlle era. In: —_ The interpersonal theory of psychiatry. New York, W.W. Norton, 1953 . cap. 15, p. 227-44.

WERNER, J. A. The use of limit setting as a therapeutic process. In: HOLMES, M. J. \& WERNER, J. A. Psychiatric nursing in a therapeutic community. New York, Macmillan, 1966. p. 43-62.

WILEY, $P$. I. Manipulation. In: CONFERENCE ON TEACHING PSICHIATRIC NURSING IN BACCALAUREATE PROGRAMS, Atlanta, 23-25 January 1967. Conference Materials. Atlanta, Southern Regional Education Board, s.d. p. 154-78.

ZAMORA, L. C. The client who generates anger. In: HABER, J. et alii. Comprehensive psychiatric nursing. New York, McGraw Hill Book, 1978. cap. 17, p. 280-305. 